University of Nebraska - Lincoln

DigitalCommons@University of Nebraska - Lincoln

Faculty Publications, Department of Child, Youth, and Family Studies

Child, Youth, and Family Studies, Department of

January 2005

Perceptions of Attachment Style and Marital Quality in Midlife

Marriage

Cody S. Hollist

University of Nebraska Lincoln, chollist2@unl.edu

Richard B. Miller

Follow this and additional works at: https://digitalcommons.unl.edu/famconfacpub

Part of the Family, Life Course, and Society Commons

Hollist, Cody S. and Miller, Richard B., "Perceptions of Attachment Style and Marital Quality in Midlife Marriage" (2005). Faculty Publications, Department of Child, Youth, and Family Studies. 43.

https://digitalcommons.unl.edu/famconfacpub/43

This Article is brought to you for free and open access by the Child, Youth, and Family Studies, Department of at DigitalCommons@University of Nebraska - Lincoln. It has been accepted for inclusion in Faculty Publications, Department of Child, Youth, and Family Studies by an authorized administrator of DigitalCommons@University of Nebraska - Lincoln. 


\title{
Perceptions of Attachment Style and Marital Quality in Midlife Marriage
}

\author{
Cody S. Hollist Richard B. Miller
}

\begin{abstract}
Based on attachment theory, Emotionally Focused Therapy (EFT) theorizes that attachment styles influence marital quality. Although research supports this relationship among young couples, no research has examined attachment styles and marital quality in midlife marriages. We examined this issue using data from 429 married people between the ages of 40 and 50. Results indicated that insecure attachment styles were associated with marital quality, whereas secure attachment was not. These results suggest that EFT therapists can help midlife couples in distressed relationships move from insecure to secure attachment styles. However, the use of EFT to help these couples who have secure attachment styles is questioned.
\end{abstract}

Key Words: attachment theory, Emotionally Focused Therapy, marriage, midlife couples.

The discipline of marriage and family therapy is moving in an evidence-based direction (Sprenkle, 2002), with clinical research becoming an important part of the discipline. As such, attention is given to those treatment models that are validated by research (Baucom, Shoham, Mueser, Daiuto, \& Stickle, 1998; Sexton, Alexander, \& Mease, in press). Simultaneously, Emotionally Focused Couples Therapy (EFT; Johnson, 2002; Johnson \& Lebow, 2000) has emerged as one of the most empirically supported couple treatment protocols.

Based on attachment theory, EFT views "distressed relationships ... as insecure bonds in which essentially healthy attachment needs are unable to be met due to rigid interaction patterns that block emotional engagement" (Johnson \& Greenberg, 1995, p. 121). Johnson and Greenberg saw the purpose of therapy as developing a more secure attachment bond within the couple relationship. Thus, the theoretical foundation of EFT is based on attachment as a conceptual means of describing and predicting adult love relationships with the assumption that the quality of romantic relationships is largely dependent upon the type of attachment between partners. EFT suggests that the security of attachment is strengthened when individuals experience their relationship as safe, and such safety enables them to deepen their emotional interactions. This experience helps partners reframe

Based on a paper presented at the annual conference of the American Association for Marriage and Family Therapy, October 2002, Cincinnati, OH. Correspondence: Cody S. Hollist, Ph.D., University of Nebraska-Lincoln, 130 Mabel Lee Hall, Lincoln, NE 68588-0236 (codyhollist@unl.edu). 
their perceptions of the dependability of others and their own worthiness of love. Further, functioning within the couple is improved as the individuals begin to convey their wants and needs and have those needs heard and addressed (Johnson, 1996).

Although previous research finds a significant relationship between attachment styles and marital quality (Bartholomew \& Horowitz, 1991; Gallo \& Smith, 2001; Kirkpatrick \& Davis, 1994), no research has examined the relationship between attachment styles and relationship quality in relationships beyond those in the early years of marriage. With a substantial relationship history and the influence of established patterns on relationships that have lasted for many years (Miller, 2000), attachment styles may have less influence. Our purpose was to use survey data from a random national sample to empirically test the relationship between attachment and marital quality for midlife individuals who have been married for at least 10 years. This will lend support for and understanding of the fundamental theoretical assumption of EFT that adult attachment influences marital quality even in midlife.

\section{Attachment}

\section{Early Attachment Theories}

Beginning in the late 1950s and early 1960s, Ainsworth, Bowlby, and others described a bond that they believed existed between primary caregivers (usually mothers) and children. Later labeled "attachment” (Ainsworth, 1964; Bowlby, 1958, 1969), it was conceptualized as the affective connection between two individuals that provides them with a firm emotional foundation from which they can interact with the world. Characteristics of this type of relationship include supportiveness, trustworthiness, caring, and acceptance (Bowlby, 1969). This bond was believed to be the foundation for future relationships and the individuals' paradigmatic views of themselves and others.
Through a study of children's reactions to being left by mother in a "strange situation" (Ainsworth, Blehar, Waters, \& Wall, 1978), Ainsworth and her colleagues identified three different styles of child behavior: secure attachment, anxious attachment, and avoidant attachment. As the first typology of attachment styles, it remains primary for childhood attachment.

Bowlby (1980) further theorized that these styles were oriented by the children's beliefs about themselves and their world. If children believed that they were worthy of love, they carried that expectation to selected relationships that were congruent with that belief. If the children believed that the world was not to be trusted, they were hesitant in emotionally connecting to others because of the perceived pending doom of the relationship. Bowlby (1980) believed that combinations of these beliefs (positive or negative beliefs about self and positive or negative beliefs about others) created the different attachment styles described by Ainsworth.

Central to the attachment process are the behaviors that maintain the relational attachment styles (Cassidy, 1999) motivated by the beliefs about self and others. The specific behaviors are important because of their function in maintaining the attachment style; that is, the attachment behaviors sustain the relationship congruent with the individual's beliefs about self and others.

Secure attachment in early life establishes a set of attachment behaviors that provide for more satisfying relationships in the future (Thompson, 1999). These behaviors change as relational contexts change, but their function remains consistent: to maintain relationship closeness in accordance with internalized beliefs. Thus, although attachment behaviors themselves change, reflecting the changing needs of the environment, individual attachment style is believed to be more reluctant to change. Changes to attachment style occur only over long periods, allowing the individual to alter internalized beliefs about self and others that were created over time (Klohnen \& Bera, 1998). 


\section{Early Application to Adult Romantic Relationships}

Typically applied to early childhood relationships, Hazen and Shaver (1987) used attachment to describe adult romantic relationships. Applying attachment to adult relationships included an adaptation of the three styles. They theorized that securely attached couples had higher marital satisfaction. In fact, research showed that securely attached couples had a lower divorce rate (Brennan \& Shaver, 1990; Hazen \& Shaver), and they reported that securely attached couples described feeling comfortable with emotional intimacy and found joy and satisfaction in close relationships. They described avoidant couples as exhibiting a fear of intimacy, and they found that avoidant individuals frequently reported feeling uncomfortable getting close to others, thinking that love partners wanted them to be closer than they felt comfortable. Ambivalent couples "experienced love as obsession, desire for reciprocation and union, emotional highs and lows, and extreme sexual attraction and jealousy" (Hazen \& Shaver, p. 515). Ambivalent couples described reluctance to get close to another because of fear that the relationship would end. Attachment behaviors associated with the ambivalent style were characterized by relationally aggressive behaviors that often pushed others away.

\section{Four-Category Model}

Although the three-category model of attachment style was adopted by some researchers (e.g., Brennan \& Shaver, 1990; Kirkpatrick \& Davis, 1994; Thompson, 1999), Bartholomew and Horowitz (1991) proposed a four-category model that included the different combinations of positive and negative beliefs about self and others. Thus, positive beliefs about self and positive beliefs about others was labeled "secure" attachment, and their description of secure attachment was consistent with secure attachment described in the three-category model. "Preoccupied" consisted of negative beliefs about self and positive beliefs about the other. Preoccupied in- dividuals were described as having a sense of unworthiness to receive love, and a belief that others are so good that they will not love them. Positive beliefs about self and negative beliefs about the other represent the "dismissing" style of attachment; these individuals feel that they are worthy of love but believe that others will reject them. Negative beliefs about self and negative beliefs about the other were labeled "fearful" attachment. This style of attachment was believed to have similar characteristics to the avoidant attachment style described by the three-category model — that is, their behavior is marked by avoidance of social settings because of the anxiety associated with connecting to others.

Research has validated the four-category model (Brennan, Clark, \& Shaver, 1998; Carver, 1997; Feeney, Noller, \& Hanrahan, 1994), and growing empirical support has prompted adoption of this model of adult attachment. Because EFT has used this model for conceptualizing adult love relationships (Johnson, 1996), we framed our study in the four-category model.

\section{Research Linking Attachment and Marriage}

Research generally supports the proposition from attachment theory that securely attached individuals have better marital relationships (e.g., Bartholomew \& Horowitz, 1991; Gallo \& Smith, 2001; Kirkpatrick \& Davis, 1994; Simpson, 1990). For example, Kobak and Hazen (1991) studied marital quality among 40 couples and found higher levels of marital satisfaction in securely attached couples. Secure attachment also is predictive of successful conflict resolution (Kobak \& Hazen), relationship independence, commitment, trust (Simpson), and positive emotions in marriage (Collins, 1996).

Research also suggests that neither attachment style of either gender is dominant in predicting marital satisfaction (Gallo \& Smith, 2001; Kirkpatrick \& Davis, 1994) — that is, men's and women's attachment styles have equal impact on a couple's perception of marital quality. 
Although research has generally found a significant relationship between attachment style and perceptions of relationship quality, the studies typically focus on young couples early in their relationships (Kirkpatrick \& Davis, 1994; Simpson, 1990). Only Kobak and Hazen (1991) had participants who were married, on average, 7 years.

Little is known about the influence of attachment styles on relationship quality in midlife couples with marriages that have lasted at least a decade. Individuals in midlife experience a number of transitions and experiences that differ from those among younger adults and that are unique to their stage in the life course. Mid-life is the period when many parents cope with adolescent children, and later launch them into young adults. Midlife is also the time when individuals face personal issues, such as menopause, family-of-origin responsibilities of caring for disabled older parents, and death of parents (Umberson, 1995). Although research indicates that societal perceptions of the "midlife crisis" are greatly exaggerated (Wethington, 2000), many people in midlife experience a period of self-evaluation, reflection, and reorientation in their lives (Hermans \& Oles, 1999).

Marital relationships in midlife also are different from those in earlier marriages (Henry \& Miller, in press; Miller, Yorgason, Sandberg, \& White, 2003). Although some midlife couples have been married only for a few years because of late marriage or remarriage, most have been married for at least 10 years, with some being married as long as 30 years. Consequently, most midlife couples have already experienced the adjustments and early transitions that characterize younger couples, such as the transition to parenthood. They also have survived the early years of marriage, which have the highest risk of divorce (Bramlett \& Mosher, 2002). In addition, midlife couples have significant relationship history and have established patterns of relating (Miller, 2000).

All of these factors suggest individual and relationship differences between midlife marriages and younger relationships, the nature of which are theoretically linked to attachment styles and marital quality. If the nuances of attachment and marital quality are different for marriages in midlife that are beyond the early years of the relationship, then the fundamentals of EFT need to be adjusted to reflect those differences.

\section{Methods}

\section{Procedure}

Questionnaires assessing different aspects of the participant's life_-including marital satisfaction, health, and mental health-were mailed to a national random sample of married people between the ages of 40 and 50. The names and addresses of 3,000 people were purchased from a marketing firm. Based on Dillman's (2000) procedures for survey research, reminder postcards were sent 2 weeks later. After another 2 weeks, a second set of questionnaires was sent to participants who had not yet responded. Finally, as a last attempt to encourage participation, researchers made phone calls to nonrespondents, inviting their participation.

Of the 3,000 questionnaires mailed, 518 were undeliverable because of bad addresses, and 566 of the original sample were either not married or were not in the desired age range. A total of 632 questionnaires were completed and returned, representing 33\% of the eligible sample. Because this study was concerned with assessing the degree to which attachment style was associated with marital quality in midlife relationships that had already experienced the adjustments and transitions of early marriage, participants who were married less than 10 years were omitted from these analyses. By 10 years of marriage, most couples who would ever become parents have done so, and the risk of divorce is reduced (Bramlett \& Mosher, 2002). Moreover, couples married at least 10 years have established patterns of relating (Miller, 2000). Thus, respondents were excluded based on 
marital status and length of marriage, so the final sample size included 429 married individuals.

\section{Sample Characteristics}

The average age of the participants was 43.7 years $(S D=2.7)$. The mean age at marriage was 24.9 years $(S D=4.7, M d n=24)$, and the participants had been married an average of 18 years $(S D=5.1)$, with a range of 10 to 30 years. They had, on average, 2.8 children $(S D=1.3)$, with a range of 0 to 10 . Forty-three percent of the sample was female, and $57 \%$ was male. The ethnicity of the sample was $90 \%$ Caucasian, 5\% African American, and 5\% other ethnicities. Forty-three percent of the sample were college graduates. Most (75\%) were employed full time, and $11 \%$ reported part-time employment. The gross family income ranged from $\$ 10,000$ to over $\$ 150,000$, with a median income between $\$ 70,000$ and $\$ 79,000(S D=\$ 38,000)$.

The sample appears to be fairly representative of the national population of married people between the ages of 40 and 50. Although the number of college graduates in the sample was above the national average, the median income of the sample is consistent with the national median income of $\$ 75,482$ for married people in this age group (U.S. Census $\mathrm{Bu}-$ reau, 2002). Moreover, the racial distribution of the sample is similar to other national studies. For example, in the Marital Instability Over the Life Course Study (Amato \& Booth, 1997), which is considered a nationally representative sample of adults, $89 \%$ of the members in their sample who were married and between the ages of 40 and 50 were Caucasian. This racial distribution compares favorably with our sample.

\section{Measurement}

Revised dyadic adjustment scale. Marital quality was measured by a self-report measure of the respondents' perceptions of the quality of their relationships. Such measures are widely used (Bradbury, Fincham, \& Beach, 2000), and self-report measures are used in research linking attachment styles and mar- ital quality (Gallo \& Smith, 2001; Kirkpatrick \& Davis, 1994). We used the 14-item Revised Dyadic Adjustment Scale (RDAS; Busby, Crane, Larsen, \& Christensen, 1995), a revision of the original 32item Dyadic Adjustment Scale (Spanier, 1976). The instrument has three subscales - consensus, satisfaction, and cohesion - that are summed to obtain an overall marital quality score. Previous research indicates that the subscales have an internal consistency of at least $\alpha=.80$, with the total RDAS having an $\alpha$ of .90. Confirmatory factor analysis has substantiated the 3-point factor structure of the scale, and its validity has been established (Busby et al.).

Measure of attachment qualities. The Measure of Attachment Qualities (MAQ; Carver, 1997) was used to measure attachment. The instrument uses the four-category model of attachment (Bartholomew \& Horowitz, 1991; Bowlby, 1973). Items are scored on a 4-point Likert-type scale ranging from 1 (disagree a lot) to 4 (agree a lot). Sample items from the four subscales are "It feels relaxing and good to be close to someone" (secure), "I prefer not to be too close to others" (avoidant), "I often worry that my partner doesn't really love me" (ambivalence-worry), and "I find that others are reluctant to get as close as I would like" (ambivalence-merger). The attachment styles labels that Carver used differ slightly from those of Bartholomew and Horowitz, but the descriptions are similar. Both label positive views of self and positive views of others as secure attachment. The avoidant category is descriptively comparable with Bartholomew and Horowitz's fearful category, with both describing negative beliefs about self and others. Ambivalence-worry is similar to the dismissing category (positive self and negative others), and the ambivalence-merger category is associated with the preoccupied category of Bartholomew and Horowitz (negative self and positive others).

The validity of the original MAQ was established by correlating it with two other attachment measures, the Relationship Questionnaire (Bartholomew \& Horowitz, 1991) and Hazan and Shaver's (1987) measure, with significant correlations reported. The 
Cronbach's $\alpha$ coefficients for secure, avoidant, ambivalence-merger, and ambivalence-worry subscales were $.72, .76, .73$, and .69 , respectively, demonstrating adequate reliability (Carver, 1997).

Because one of the items was inadvertently omitted from the questionnaire used in this study, only 13 of the original 14 items were included in the analyses. The results of psychometric analyses show that the modified scales remain an adequate measure of attachment despite the loss of the item. The remaining 13 items loaded onto the intended four factors in a principal components factor analysis and the itemized factor loadings for the subscale items were similar to those loadings reported by Carver (1997). The factor loadings for the four remaining items on the avoidance scale, using varimax rotation, were .81 for item 1, .87 for item 2, .75 for item 3, and .75 for item 4 . The Cronbach's $\alpha$ coefficient for the modified sub-scale was .85 , indicating adequate reliability. A measurement model (Byrne, 2001) was tested to assess the effect of the missing variable on the subscale's ability to predict changes in the latent variable, attachment, and compare it with the other subscales. Evaluation of the SEM analysis output showed that, out of the four subscales, the avoidance subscale remained the strongest predictor of the latent construct, with a coefficient of -.16, compared with -.15 for ambivalence-merger, -.15 for ambivalence-worry, and .06 for secure. These results further indicate that the MAQ is psychometrically sound despite the loss of one item.

\section{Analytic Strategy}

Structural equation modeling (SEM) was used to estimate the conceptual model (Byrne, 2001), and the computer program AMOS was used to compute the structural model indexes (Arbuckle, 1996; see Figure 1). Kline (1998) stated that the reporting of goodness-of-fit statistics should include the chi-square, root mean square error of approximation (RMSEA), goodness-of-fit index (GFI), and Tucker-Lewis index. These statistics provide a comprehensive assessment of the fit of the model to the data (Boomsma, 2000).

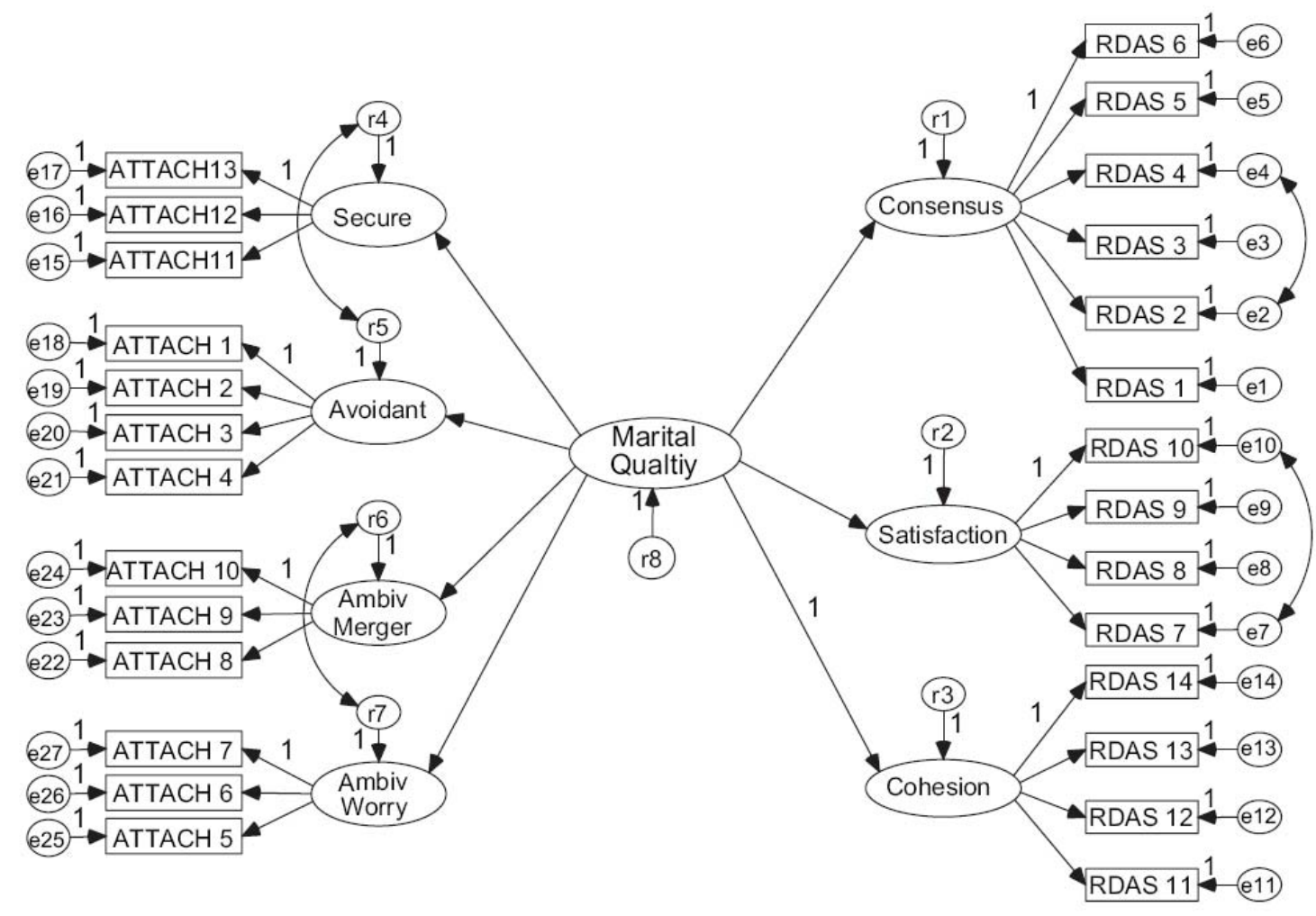

Figure 1. Full Hypothesized Structural Equation Model of Marital Quality and Attachment Styles. 
The chi-square statistic is mainly an important goodness-of-fit statistic in small samples (Kline), making it less useful for our study. Scores of less than .05 for the RMSEA are considered good fitting models, and .08 is considered adequate (Byrne). The RMSEA is an especially important statistic with larger samples (Boomsma). The GFI and Tucker-Lewis indexes indicated goodness of fit with scores of .90 and higher (Bryne). The parsimony ratio also is used to evaluate fit (Kline). This index evaluates the degree of appropriateness of model complexity compared with the data. For example, if there are unnecessary variables included in the conceptual model, it will lower the parsimony ratio. Thus, a parsimony ratio closer to 1.0 indicates that the model is organized as succinctly as possible without losing valuable information. In most cases, acceptable parsimony ratios are above .60 (Byrne).

The analysis was conducted in two stages. The confirmatory factor analysis of both instruments occurred first to assess the factor structure, reliability, and applicability of the instruments. Next, we examined the fit of the overall model to the data. After an adequate fit was demonstrated, we tested the research hypotheses by examining the regression coefficients between the attachment styles and marital quality.

Several demographic variables were initially included in the model as control variables. Because the number of years married, ethnicity, and income have been shown to associate with marital quality (Glenn, 1990; VanLaningham, Johnson, \& Amato, 2001), they were included to account for any possible differences caused by demographic characteristics. Because preliminary analyses results showed that the control variables were not significant in the model, they were omitted to increase the parsimony of the model.

Because of potential gender differences in the relationship between attachment and marital quality, analyses were conducted to account for the effect of gender. Conducting a nested group comparison allowed for the examination of the association between attachment styles and marital quality for females and males separately by calculating how well the model fit the data for both groups (Bryne, 2001). Although this type of analysis also allows researchers to make modifications to each group individually, the AMOS modification indexes suggested that similar adjustments be made, and the final model for both men and women was the same. As such, only one model is shown as Figure 1.

\section{Results}

\section{Correlations between Variables}

A correlation matrix of the variables was first examined to determine the correlational structure of the data (see Table 1). Findings indicated that the RDAS was significantly correlated with the avoidant subscale, the ambivalence-worry subscale, and the ambivalence-worry sub-scale for both men and women. However, it was not significantly associated with the secure subscale.

\section{Confirmatory Factor Analysis}

The confirmatory factor analysis (CFA) of the RDAS yielded results indicating that the RDAS was appropriate for this analysis. In the CFA, three categories emerged, and the RDAS items identified by the three categories were consistent with the items in the subscales. Initial model fit statistics prior to modification were a RMSEA of .08, a Tucker-Lewis index of .91, and a GFI of .92.

Modification indexes suggested that restraining two additional parameters that covaried would improve the fit of the model for the RDAS. The first covariance-linked questions were related to demonstrations of affection (e4) and sexual relations (e2), which is conceptually sound. The other covariance linked an item asking how often they get on each other's nerves (e10), and how often they think about divorce (e7). In this case, it was also logical that these would be related. The resulting modifications improved the model's fit: RMSEA for the 
CFA was .04, Tucker-Lewis Index was .98, and GFI was .96.

The results of the CFA on the MAQ indicated that the four categories designed by Carver (1997) were validated for these data, and the outcome showed that the MAQ was appropriate for use. Initial values of model fit statistics indicated that changes needed to be made to better fit the data and the model. Modification indexes suggested two changes. There was a high covariance between secure and avoidant attachment styles, and another covariance between both of the ambivalence subscales. Both covariances made theoretical sense if the attachment styles are to reflect their implications for beliefs about self and others. Given the theoretical justification, the errors for these two pairs of parameters were covaried in the final model, resulting in fit statistics of GFI $=.96$, TuckerLewis Index $=.97$, and RMSEA $=.05$. These fit statistics illustrate an adequate goodness of fit between the MAQ and the data.

\section{Testing the Conceptual Model}

The complete conceptual model fit the data well and explained the relationship between variables in the simplest way possible without losing valuable information. The gender comparison nested group model had a RMSEA of .03. Additional evidence of goodness of fit was found in the Tucker-Lewis Index, (.95) and the GFI (.87). The parsimony ratio of our model was .89. The combined model chi-square statistic, $X^{2}$ $(626, N=429)=878.1, d f=626, N=429$, was significant at the .00 level; however, because of the influence that sample size has on this statistic, it is less important in this study as a goodness-of-fit measure (Bryne, 2001). Based on sample demographics and model fit statistics, the results generated are trustworthy and generalizable to the larger population.

As indicated in Table 2 and Figure 2, secure attachment was not related to marital quality for either men or women in this sample. The path coefficients were $.08, p>.05$, and $.07, p>.05$ for females and males, respectively. Thus, the presence of secure attachment behaviors was not related to perceptions of marital quality.

For women, all three insecure attachment subscales were associated with marital quality. The standardized path coefficients were $-.24, p<.01$ for avoidant; $-.53, p<.01$ for ambivalence-worry; and $-.36, p<.01$ for ambivalence-merger. For males, the

Table 1. Correlations for Attachment Style and Marital Satisfaction in Women and Men

\begin{tabular}{|c|c|c|c|c|c|c|c|c|c|c|}
\hline \multirow[b]{2}{*}{ Variables } & \multicolumn{5}{|c|}{ Women $(N=185)$} & \multicolumn{5}{|c|}{$\operatorname{Men}(N=244)$} \\
\hline & 1 & 2 & 3 & 4 & 5 & 1 & 2 & 3 & 4 & 5 \\
\hline $\begin{array}{l}\text { 1. Marital } \\
\text { satisfaction }\end{array}$ & - & & & & & - & & & & \\
\hline 2. Secure & .06 & - & & & & .08 & - & & & \\
\hline 3. Avoidant & $-.16^{*}$ & $-.56 * * *$ & - & & & $-.17 * *$ & $-.41 * * *$ & - & & \\
\hline $\begin{array}{l}\text { 4. Ambivalence- } \\
\text { worry }\end{array}$ & $-.42 * * *$ & $-.16^{*}$ & $.24 * *$ & - & & $-.47 * * *$ & -.05 & $.18 * *$ & - & \\
\hline $\begin{array}{l}\text { 5. Ambivalence- } \\
\text { merger }\end{array}$ & $-.33 * * *$ & $-.16^{*}$ & $.31 * * *$ & $.45 * * *$ & - & $-.23 * * *$ & $-.15^{*}$ & .11 & $.37 * * *$ & - \\
\hline$M$ & 46.90 & 9.57 & 7.85 & 5.50 & 5.70 & 48.01 & 9.10 & 8.55 & 5.58 & 5.90 \\
\hline$S D$ & 9.64 & 1.56 & 2.54 & 1.92 & 1.60 & 8.91 & 1.71 & 2.16 & 1.70 & 1.63 \\
\hline Range & $10-65$ & $6-12$ & $4-1$ & $3-12$ & $3-10$ & $13-65$ & $3-12$ & $4-16$ & $3-12$ & $3-11$ \\
\hline
\end{tabular}

${ }^{*} p<.05 .{ }^{* *} p<.01 .{ }^{* * *} p<.001$. 


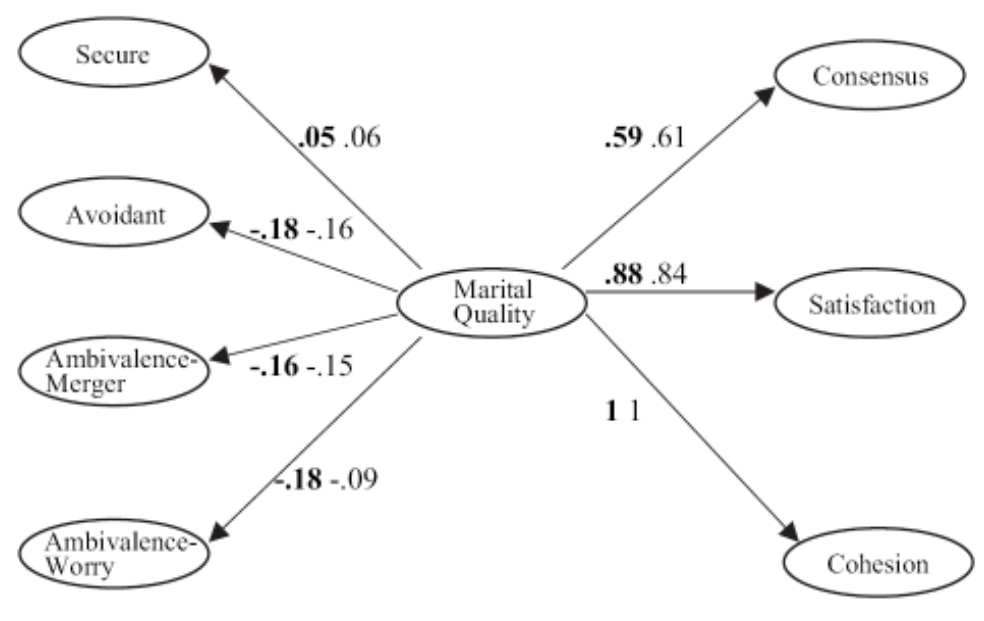

Figure 2. Gender Comparison Model. Note. Women path coefficients are bold.

variables for avoidant and ambivalence-merger were associated with marital quality, with path coefficients of $-.20, p<.01$ and $-.26, p<.01$ respectively. However, the ambivalence-worry style was not associated with marital quality among the men, with an unstandardized path coefficient of $-.10, p>.05$. As expected, all of the insecure attachment variables were inversely related to marital quality; thus, insecure attachment variables were associated with lower levels of marital quality.

These results indicate that there are few gender differences in the association between attachment styles and marital quality. The male and female path coefficients were almost identical, except for the ambivalence-worry style.

Marital quality scores accounted for $5.7 \%$ of the variance for avoidant attachment for women and $4 \%$ for men. For the avoidant-merger style of attachment, marital quality scores accounted for $12.9 \%$ of the variance for women and $6.8 \%$ for men. Avoidant-worry showed that the largest amount of influence was due to marital quality, with $27.6 \%$ of the variance for women being associated with marital quality, and $44.4 \%$ for men.

\section{Discussion}

Although research with younger people in relationships finds a positive relationship between all attachment styles and relationship quality, we illustrated that secure attachment has less influence on relationship quality among individuals who have been mar-

Table 2. Unstandardized, Standardized, and Significance Levels for Key Elements of the Model in Figure 1 Organized by Gender ${ }^{\mathrm{a}}$

\begin{tabular}{|c|c|c|c|c|c|c|}
\hline \multirow[b]{2}{*}{ Parameter Estimate } & \multicolumn{3}{|c|}{ Women } & \multicolumn{3}{|c|}{ Men } \\
\hline & Unstandardized & Standardized & $p$ & Unstandardized & Standardized & $p$ \\
\hline Secure $\rightarrow$ Marital quality & $.05(.06)$ & .08 & .36 & $.07(.07)$ & .07 & .35 \\
\hline Avoidant $\rightarrow$ Marital quality & $-.19(.07)$ & -.24 & .01 & $-.17(.07)$ & -.20 & .01 \\
\hline $\begin{array}{l}\text { Ambivalence-worry } \rightarrow \text { Marital } \\
\quad \text { quality }\end{array}$ & $-.18(.05)$ & -.53 & .00 & $-.10(.06)$ & -.67 & .13 \\
\hline $\begin{array}{l}\text { Ambivalence-merger } \rightarrow \text { Marital } \\
\quad \text { quality }\end{array}$ & $-.17(.04)$ & -.36 & .00 & $-.15(.05)$ & -.26 & .00 \\
\hline
\end{tabular}

Notes. $\chi^{2}=878, d f=626, p<.001, N=429$; RMSEA $=.03 ; \mathrm{GFI}=.87$; Tucker-Lewis $=.95 ;$ parsimony ratio $=.89$.

${ }^{a}$ Standard errors in parentheses. 
ried for at least 10 years. This result was true for both women and men. Once established, this relational security provides a firm foundation, likely increasing resilience to life difficulties. Inversely, insecurely attached individuals are more vulnerable to the effects of contextual stressors, and their attachment styles are unstable. In other words, secure attachment behaviors become more stable and resilient over time. Research has stated that relationships beyond the early years of marriage are characterized by established properties (Miller, 2000). Patterns of interaction in the relationship and general perceptions of the quality of the relationship are established early in the relationship and remain over time. It is probably during these early years that attachment styles and behaviors have the greatest impact on perceptions of the quality of the relationship. However, after the patterns of relating and perceiving are established, they tend to be stable throughout the course of the marriage. We propose that, whereas in the early years of marriage, interactional dynamics are fluid, much like in the early stages of life, if one establishes securely attached interactional dynamics over time, those patterns make the secure attachment style resistant to contextual relationship stressors. Consequently, secure attachment styles and behaviors may have less influence on marital quality in relationships that are at least 10 years in duration.

Attachment theory has an implicit supposition that people naturally seek secure attachments (Bowlby, 1969). Once these secure attachment behaviors are established, relational interactions reflect those styles with less instability. Likewise, variations of marital quality in midlife relationships seem to be more influenced by insecure attachment behaviors than secure behaviors. Because people who have insecure attachment styles desire and seek secure attachment in their intimate relationships, these insecure attachment styles might remain fluid and malleable in midlife, maintaining their association with perceptions of marital quality.

Comparing the research with younger married individuals (Kirkpatrick \& Davis, 1994; Kobak \& Ha- zen, 1991), our results with midlife married individuals indicate that secure attachment has a declining association with marital quality over the life course. Future research needs to make direct statistical comparisons of younger and midlife couple relationships to explicitly test this hypothesis. Ultimately, longitudinal research is needed to examine the potentially changing influence of attachment styles on marital quality over the life course.

Results of the tests to assess gender differences found little divergence. In general, insecure attachment styles were significantly associated with marital quality, whereas the secure attachment style was not, with path coefficients between males and females being similar. The only gender difference found was with the ambivalence-worry style, which was associated with marital quality for women but not men. Attachment theorists describe the ambivalence-worry style of attachment as positive view of self and negative view of others (Bartholomew \& Horowitz, 1991; Carver, 1997). Consequently, the pattern of women viewing themselves positively and viewing others negatively has a negative association with their marital quality, whereas the same pattern has no significant effect on men's marital quality. These results suggest the possibility that women's perception of their trust of others may have a significant influence on their marital quality, while trust may have less of an influence on men's perception of their marriage. Future research needs to explore the possible role of trust in the association between attachment styles and marital quality as a possible explanation for these gender differences.

The results of the study also provide additional evidence supporting the four-category model of attachment, and the confirmatory factor analysis validated the factor structure of the Measure of Attachment Qualities. Thus, although the three-factor model of attachment with the labels of secure, anxious, and avoidant styles is well known, there is evidence that adult attachment may be best characterized by four factors that include the perspective of positive and negative beliefs about self and significant others. 


\section{Implications for Therapists}

Because EFT is one of the few empirically validated models for treating couples, our results have important implications for marriage and family therapists. The results generally support the theoretical proposition of EFT that attachment styles have an important influence on the quality of relationships in marriages that are at least a decade in length. EFT unequivocally proposes that, because of the impact of attachment styles on marital quality, a key goal of therapy is to alter insecure attachment behaviors as a way to increase marital satisfaction (Johnson, 1996). More explicitly, the results of this study support this postulate by validating that changes in the insecure styles of attachment influence perceived marital quality in midlife married individuals. Thus, the focus of therapy with these couples should be on insecure attachment behaviors, (i.e., behaviors designed to maintain the relationship, consistent with one's negative beliefs about self and/or others). Decreasing the frequency and intensity of these behaviors will increase the perceived marital satisfaction.

A significant implication of these results concerns the applicability of EFT to working with midlife married individuals. These findings suggest that EFT may be an appropriate treatment model when insecurely attached midlife couples come to couple therapy seeking resolution to their relationship problems. However, those midlife couples who already have secure attachments might not benefit from a model that focuses on changing attachment styles. EFT has not explicitly addressed what to do with secure attachment behaviors, but is based on the notion that couples seeking therapy have insecure attachments that drive the need for therapy. Perhaps securely attached couples would rarely, if ever, need therapy. Certainly, more research needs to be done to examine whether all couples who seek therapy are doing so as a result of insecure attachment behaviors.

The results of the study expand the practical application of EFT by further delineating how EFT therapists might focus on insecure attachment behaviors. As EFT therapy helps to alter the insecure attachment behaviors and reestablish securely attached behaviors, the individuals' perception of relational quality will likely improve. Summarizing the EFT intervention process, an important step in therapy is to investigate the couple's negative interaction cycle or their insecure attachment behaviors (Johnson, 1996). Johnson further explains that it is crucial to explore the underlying needs and emotions associated with the current cyclical process - that is, underlying needs and emotions guide the insecure attachment behaviors, which have a direct effect on current marital dissatisfaction. It is within this step that the current study provides the greatest contribution by confirming that insecure attachment behaviors are related to perceptions of relational satisfaction in midlife married individuals.

\section{References}

Ainsworth, M. D. S. (1964). Patterns of attachment behavior shown by the infant in interaction with his mother. Merrill-Palmer Quarterly, $10,51-58$.

Ainsworth, M. D. S., Blehar, M. S., Waters, E., \& Wall, S. (1978). Patterns of attachment: A psychological study of the strange situation. Hillsdale, NJ: Erlbaum.

Amato, P., \& Booth, A. (1997). A generation at risk: Growing up in an era of family upheaval. Cambridge, MA: Harvard University Press.

Arbuckle, J. L. (1996). Amos user's guide: Version 3.6. Chicago: SPSS

Bartholomew, K., \& Horowitz, L. M., (1991). Attachment styles among young adults: A test of a four-category model. Journal of Personality and Social Psychology, 61, 226-244.

Baucom, D. H., Shoham, V., Mueser, K. T., Daiuto, A. D., \& Stickle, T. R. (1998). Empirically supported couple and family interventions for marital distress and adult mental health problems. Journal of Consulting and Clinical Psychology, 66, 53-58.

Boomsma, A. (2000). Reporting analysis of covariance structures. Structural Equation Modeling, 7, 446-483.

Bowlby, J. (1958). The nature of the child's tie to his mother. International Journal of Psycho-Analysis, 39, 350-373.

Bowlby, J. (1969). Attachment and loss Vol. 1.: Attachment. New York: Basic Books.

Bowlby, J. (1973). Attachment and loss Vol. 2.: Separation, anxiety, and anger. New York: Basic Books.

Bowlby, J. (1980). Attachment and loss Vol. 3.: Loss: Sadness and depression. New York: Basic Books.

Bradbury, T. N., Fincham, F. D., \& Beach, S. R. H. (2000). Research on the nature and determinants of marital satisfaction: A decade in review. Journal of Marriage and the Family, 62, 964-981.

Bramlett, M. D., \& Mosher, W. D. (2002). Cohabitation, marriage, di- 
vorce, and remarriage in the United States. Vital Health Statistics (Series 23, No. 22).

Brennan, K. A., Clark, C. L., \& Shaver, P. R. (1998). Self-report measurement of adult attachment: An integrative overview. In J. A. Simpson $\&$ W. S. Rholes (Eds.), Attachment theory and close relationships (pp. 46- 76). New York: Guilford Press.

Brennan, K. A., \& Shaver, P. R. (1990) Dimensions of adult attachment, affect regulation, and romantic relationship functioning. Personality and Social Psychology Bulletin, 21, 267-283.

Busby, D. M., Crane, D. R., Larson, J. H., \& Christensen, C. (1995). A revision of the Dyadic Adjustment Scale for use with distressed and nondistressed couples: Construct hierarchy and multidimensional scales. Journal of Marital and Family Therapy, 21, 289-308.

Byrne, B. M. (2001). Structural equation modeling with Amos: Basic concepts, applications, and programming. Mahwah, NJ: Erlbaum.

Carver, C. S. (1997). Adult attachment and personality: Converging evidence and a new measure. Personality and Social Psychology Bulletin, $23,865-883$.

Cassidy, J. (1999). The nature of the child's ties. In J. Cassidy \& P. R. Shaver (Eds.), Handbook of attachment: Theory, research, and clinical applications (pp. 3-20). New York: Guilford Press.

Collins, N. L. (1996). Working models of attachment: Implications for explanation, emotion, and behavior. Journal of Personality and Social Psychology, 71, 810-832.

Dillman, D. A. (2000). Mail and internet surveys: The tailored design method. New York: Wiley.

Feeney, J. A., Noller, P., \& Hanrahan, M. (1994). Assessing adult attachment: Developments in the conceptualization of security and insecurity. In B. B. Sperling \& W. H. Bernam (Eds.), Attachment in adults: Clinical and developmental perspectives (pp. 128-152). New York: Guilford Press.

Gallo, L. G., \& Smith, T. W. (2001). Attachment style in marriage: Adjustment and responses to interaction. Journal of Social and Personal Relationships, 18, 263-289.

Glenn, N. D. (1990). Quantitative research on marital quality in the 1980s: A critical review. Journal of Marriage and the Family, 52, $818-831$

Hazan, C., \& Shaver, P. (1987) Romantic love conceptualized as an attachment process. Journal of Personality and Social Psychology, 52, 511-524.

Henry, R. G., \& Miller, R. B. (in press). Marital problems occurring in midlife: Implications for couples therapists. American Journal of Family Therapy.

Hermans, H. J., \& Oles, P. K. (1999). Midlife crisis in men: Affective organization of personal meanings. Human Relations, 52, 1403-1425.

Johnson, S. M. (1996). The practice of emotionally focused marital therapy: Creating connection. New York: Brunner/Mazel.

Johnson, S. M. (2002). Marital Problems. In D. Sprenkle (Ed.), Effectiveness research in marriage and family therapy (pp. 163-190). Alexandria, VA: American Association for Marriage and Family Therapy.

Johnson, S. M., \& Greenberg, L. S. (1995). The emotionally focused approach to problems in adult attachment. In N. S. Jacobson \& A. S.
Gurman (Eds.), Clinical handbook of couple therapy (pp. 121-141). New York: Guilford Press.

Johnson, S. M., \& Lebow, J. (2000). The "coming of age" of couple therapy: A decade review. Journal of Marital and Family Therapy, 26, $23-38$.

Kirkpatrick, L. A., \& Davis, K. E. (1994). Attachment style, gender, and relationship stability: A longitudinal analysis. Journal of Personality and Social Psychology, 66, 502-512.

Kline, R. B. (1998). Principles and practice of structural equation modeling. New York: Guilford Press.

Klohnen, E., \& Bera, S. (1998). Behavioral and experiential patterns of avoidantly and securely attached women across adulthood: A 31 year longitudinal perspective. Journal of Personality and Social Psychology, $66,502-512$.

Kobak, R. R., \& Hazen, C. (1991). Attachment in marriage: Effects of security and accuracy of working models. Journal of Personality and Social Psychology, 60, 861-869.

Miller, R. B. (2000). Misconceptions about the U-shaped curve of marital satisfaction over the life course. Family Science Review, 13, 60-73.

Miller, J. B., Yorgason, J., Sandberg, J. G., \& White, M. B. (2003). Problems that couples bring to therapy: A view across the family life cycle. American Journal of Family Therapy, 31, 395-407.

Sexton, T. L., Alexander, J. F., \& Mease, A. L. (2004). Levels of evidence for the models and mechanism of therapeutic change in family and couple therapy. In M. J. Lambert (Ed.), Bergin and Garfield's handbook of psychotherapy and behavior change (5th ed, pp. 590-646). New York: Wiley.

Simpson, J. A. (1990). Influence of attachment styles on romantic relationships. Journal of Personality and Social Psychology, 59, 971-980.

Spanier, G. B. (1976). Measuring dyadic adjustment: New scales for assessing the quality of marriage and similar dyads. Journal of Marriage and the Family, 38, 15-28.

Sprenkle, D. H. (Ed.). (2002). Effectiveness research in marriage and family therapy. Alexandria, VA: American Association for Marriage and Family Therapy.

Thompson, R. A. (1999). Early attachment and later development. In J. Cassidy \& P. R. Shaver (Eds.), Handbook of attachment: Theory, research, and clinical applications (pp. 265-286). New York: Guilford Press.

Umberson, D. (1995). Marriage as support or strain? Marital quality following the death of a parent. Journal of Marriage and the Family, 57, 709-723.

U.S. Census Bureau. (2002, March). Age of reference person, by total money income in 2001, type offamily, race, and Hispanic origin of reference person. Retrieved July 2, 2003, from CPS Annual Demographic Supplement Online via FERRET: http://ferret.bls.census.gov/macro/032002/ faminc/new02_006.htm

VanLaningham, J., Johnson, D. R., \& Amato, P. (2001). Marital happiness, marital duration, and the U-shaped curve: Evidence from a fivewave panel study. Social Forces, 78, 1313-1341.

Wethington, E. (2000). Expecting stress: Americans and the "midlife crisis." Motivation and Emotion, 24, 85-102. 